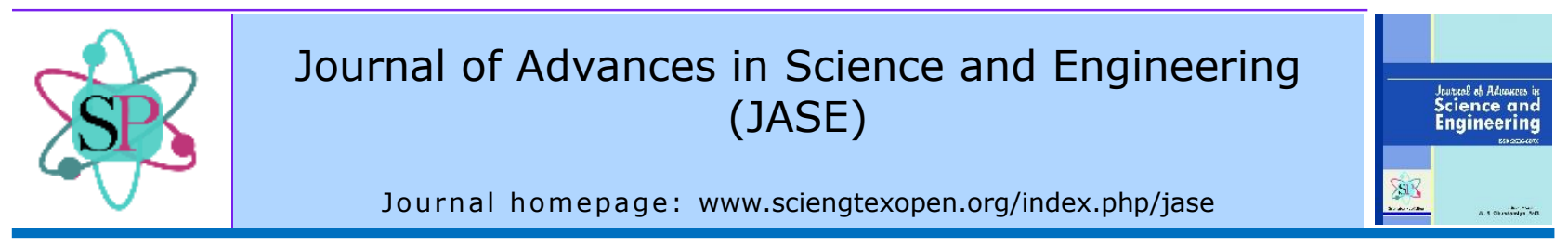

\title{
Effects of energy band structure on gallium arsenide based MOSFET
}

\author{
Wut Hmone Kyaw ${ }^{a, *}$, May Nwe Myint Aye ${ }^{b}$ \\ ${ }^{a}$ Department of Electronic Engineering, Technological University (Sagaing), Sagaing, Myanmar; ${ }^{b}$ Department \\ of Electronic Engineering, Technological University (Sagaing), Sagaing, Myanmar
}

\section{ARTICLE INFO}

\section{Article history:}

Received 30 June 2020

Received in revised form 16 July 2020

Accepted 18 July 2020

Available online

18 July 2020

\section{Keywords:}

Band-gap

Energy band

Gallium Arsenide

MOSFET

Semiconductor material

\begin{abstract}
This research work is focused on material science and semiconductor engineering. It emphasized on the semiconductor material such as Gallium arsenide (GaAs). The Gallium arsenide semiconductor material was used as a group III-V compound for metal-oxide semiconductor field effect transistor (MOSFET) modeling. The bandgap energy structures were analyzed by using material parameters such as Varshni parameters, temperature and doping concentrations. Then, an electrical characteristic was carried out depending on the current and voltage relationship. The current flowing in the device is associated with a gate voltage applied to the device. From this paper, the analysis of MOSFET modeling was investigated using mathematical equations and MATLAB simulation.
\end{abstract}

\section{Introduction}

Gallium arsenide (GaAs) is one type of semiconductor material compounds and it has a zinc blende crystal structure. The material Gallium and the material Arsenide are known as group III and $\mathrm{V}$ materials in the periodic table of semiconductor engineering. The two materials of gallium and arsenide have the same quantities of the element gallium ( $\mathrm{Ga}$ ) and element arsenic (As), respectively. The structure of gallium arsenide semiconductor material is the result of two equivalent interpenetrating face-centered cubic (FCC) lattices of gallium and arsenide [1]. Fig. 1 shows the crystal structure of GaAs.

Gallium arsenide semiconductor material can be doped to form both $\mathrm{n}$ - and $\mathrm{p}$ - type materials. Tellurium, selenium, sulfur, which are group-VI elements, are donors to gallium arsenide. Group II elements, for example cadmium, magnesium, zinc, and are known to be acceptors with respect to GaAs material. In gallium arsenide compound, group IV elements such as silicon and carbon are known to be amphoteric dopants [3].

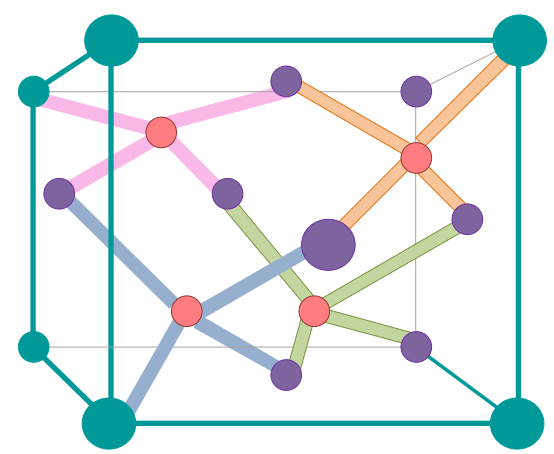

Fig. 1 Crystal structure of GaAs semiconductor material [2]

\footnotetext{
* Corresponding author.
}

Wut H. Kyaw (iD https://orcid.org/0000-0001-6614-059X e-mail: lillian.wuthmone@gmail.com

ISSN: 2636-607X; e-ISSN: 2736-0652 / () 2020 the authors. Published by Sciengtex. This is an open access article under CC BY-NC-ND license (http://creativecommons.org/licenses/by-nc-nd/4.0/) 
Although silicon is known to be a gallium site when the doping concentration level is below $10^{19} \mathrm{~cm}^{-3}$, the silicon is like a donor. As there are two dissimilar atoms in the compound, impurity atoms such as in group II, group IV and group VI can act as low donors and acceptors. Moreover, doping can create GaAs semi-insulating [4].

One of the great advantages of gallium arsenide semiconductor material compound is that the material has semi-insulating properties in some device fabrication technologies. These properties make it a low capacitance substrate; hence, the device can increase its speed [1]. It can also simplify the device isolation, which could be accomplished in some cases. Actually, semi-insulating gallium arsenide could result in a resistivity as high as $10^{8} \mathrm{Qcm}$. Otherwise, the value of resistivity of semi-insulating GaAs is about $10^{7} \Omega \mathrm{cm}$ in practical usages. Therefore, there are different techniques of doping and altering the properties of GaAs [5], [6]

MOSFETs (metal-oxide-semiconductor field effect transistors) are offered in enhancement and depletion modes of operation. Moreover, the enhancement and depletion types of MOSFETs are categorized into p-channel and $\mathrm{n}$-channel types of transistor as shown in Fig. 2. The n-channel transistor has n-channel region between source and drain. The gate and source terminals are heavily doped with n-type semiconductor materials [7].
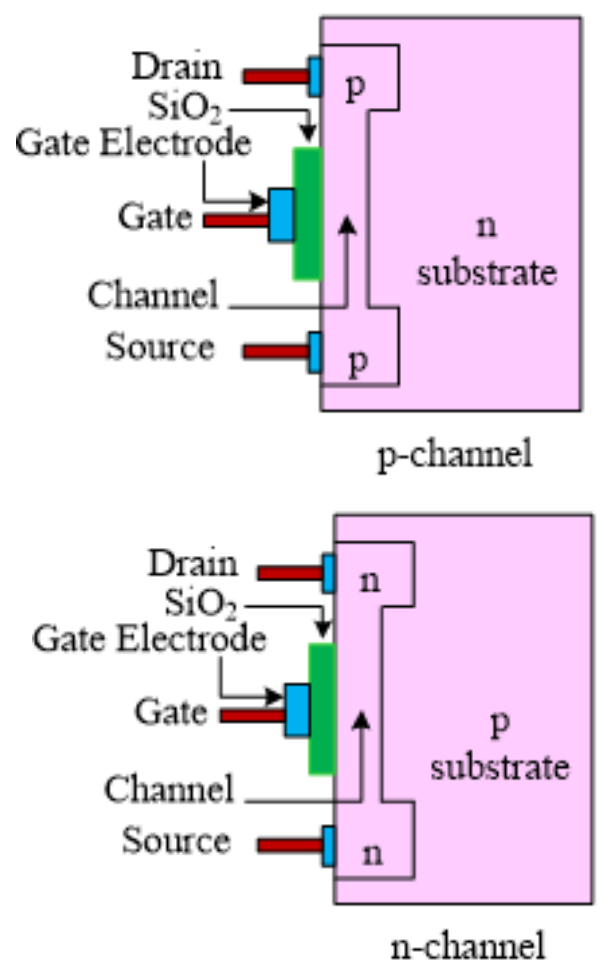

Fig. 2 P-Channel and N-Channel MOSFET [9]
The substrate region is doped with p-type semiconductor material to form $p$-doped GaAs. The drain current of the device flows between source and drain electrode and this current occurs because of electron flows. The current flowing through the device is controlled by the gate voltage [8].

\section{Properties of Gallium Arsenide (GaAs) Material}

GaAs is a semiconductor material, which has a zinc blende lattice structure. The lattice structure of this compound is very comparable to the lattice structure of diamond. However, the zinc blende structure differs from the diamond as there are two unique types of atoms in the lattice. In the GaAs, Ga atoms are occupied as four atoms and the rests are occupied as As-atoms. The important characteristics and properties of both structures are that atoms of both structures are linked together to form a tetrahedron [4]. The knowledge on different kinds of crystal structures is very important in determining the distances between neighboring atoms in a crystal. Also, the values of lattice constant are essential to control some of the important properties (physical and electrical) of crystals in a semiconductor [10]. Note that, the distance between two neighboring atoms in a lattice may be less than the lattice constant depending on the crystal structure. Table 1 shows the properties of the gallium arsenide material [4].

The gallium arsenide material also has a covalent bonding with some ionic character. GaAs is utilized in the fabrication (manufacture) of several devices like solar cells, laser diodes, infrared light-emitting diodes, optical windows and monolithic microwave integrated circuits. GaAs can also be utilized as a substrate material at the semiconductor laboratory in performing the epitaxial growth of compounds such as InGaAs and AlGaAs [10], [11]. Besides, GaAs has a wide and direct band gap of $1.42 \mathrm{eV}$. On the other hand, silicon has an indirect band gap of $1.1 \mathrm{eV}$. So, GaAs is a very valuable material for switches, high speed operating as well as optoelectronic devices [12]. The value of the energy gap for GaAs at room temperature is $1.42 \mathrm{eV}$, but it is assumed to be $1.53 \mathrm{eV}$ at $0 \mathrm{~K}$ [13]. Fig. 3 shows the band structure of gallium arsenide.

Table 1 Properties of GaAs material [4]

\begin{tabular}{cccc}
\hline \hline Type & $\begin{array}{c}\text { Crystal } \\
\text { Structure }\end{array}$ & $\begin{array}{c}\text { Lattice } \\
\text { Constant at } \\
300 \mathrm{~K}(\AA)\end{array}$ & $\begin{array}{c}\text { Dielectric } \\
\text { constant }\end{array}$ \\
\hline $\begin{array}{c}\text { Group III-V } \\
\text { Compound }\end{array}$ & $\begin{array}{c}\text { Zinc } \\
\text { blende }\end{array}$ & 5.6533 & 13.1 \\
\hline \hline
\end{tabular}




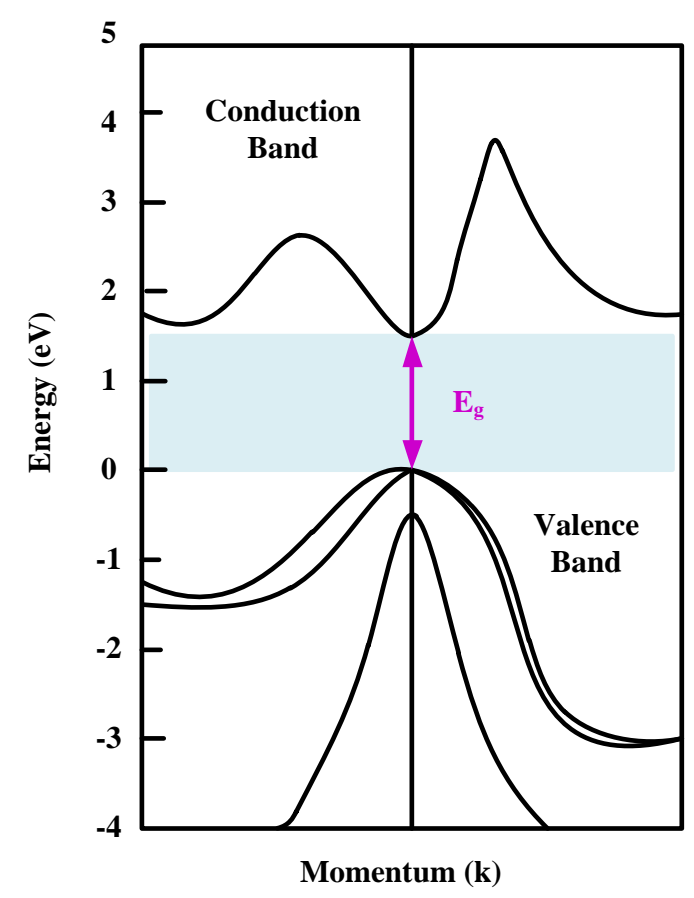

Fig. 3 Band structure of GaAs [1]

\section{Temperature Dependence of Band-Gap Energy}

The band-gap energy was examined by the temperature dependence parameters. The energy level expressed in terms of temperature ranges for the material was surveyed by Varshni in 1967 . The following formula expresses the energy band-gap depending on the temperature and Varshni's parameters of the material [5]:

$$
\mathrm{E}_{\mathrm{g}}=\mathrm{E}_{\mathrm{g}}(0 \mathrm{~K})-\frac{\alpha \mathrm{T}^{2}}{\mathrm{~T}+\beta}
$$

where $E_{\mathrm{g}}$ is energy band gap of the material, $T$ is temperature value $(\mathrm{K})$, and $\alpha$ and $\beta$ are fitting (otherwise called Varshni) parameters.

The band gap energy as a function of temperature for several semiconductor materials is along with the values for fitting parameters. Assume that the change in bandgap energy is the dominant factor in defining the voltage of the device depending on the temperature values. The temperature reliance of the forward voltage follows directly from the temperature dependence of the band gap energy. Table 2 shows the Varshni parameter values for gallium arsenide.

Table 2 Parameters for Materials [14]

\begin{tabular}{cccc}
\hline \hline Materials & $\mathrm{E}_{g}(\mathrm{OK})$ & $\begin{array}{l}\mathrm{a}\left(10^{-4}\right. \\
\mathrm{eV} / \mathrm{K})\end{array}$ & $\beta(\mathrm{K})$ \\
\hline $\mathrm{Si}$ & 1.170 & 4.73 & 636 \\
$\mathrm{Ge}$ & 0.744 & 4.77 & 235 \\
$\mathrm{GaAs}$ & 1.519 & 5.41 & 204 \\
\hline
\end{tabular}

\section{Implementation Procedure for Energy Band Diagram}

For the research of energy band, donor concentration $\left(N_{\mathrm{d}}\right)$ is considered as $2 \times 10^{17}$ $\mathrm{cm}^{-3}$. The conduction band edges $\left(E_{\mathrm{CN}}-F_{\mathrm{N}}\right)$ is required to consider at room temperature $(\mathrm{T}=300 \mathrm{~K})$. The value of charge, $q$ is $1.6 \mathrm{x}$ $10^{-19} \mathrm{C}$. The implementation for the energy band result is in the following step by step procedure.

The Boltzmann's constant is:

$$
\mathrm{k}_{\mathrm{B}}=8.6175 \times 10^{-5} \mathrm{eV} / \mathrm{K}
$$

The electron effective mass and that of holes for GaAs are:

$$
\begin{aligned}
& \mathrm{m}_{\mathrm{e}}^{*}=0.0665 \mathrm{~m}_{\mathrm{b}} \\
& \mathrm{m}_{\mathrm{h}}^{*}=0.50 \mathrm{~m}_{0}
\end{aligned}
$$

The dielectric constant for GaAs is:

$$
\varepsilon_{\mathrm{n}}=13.1 \varepsilon_{0}
$$

The vacuum permittivity is:

$$
\varepsilon_{0}=8.854 \times 10^{-14} \mathrm{As} /(\mathrm{Vcm})
$$

The band-gap energy, $E_{g n}$ for gallium arsenide semiconductor is:

$$
\mathrm{E}_{\mathrm{gn}}=1.424 \mathrm{eV}
$$

The concentration of the conduction band is considered as:

$$
\mathrm{N}_{\mathrm{c}}=2.51 \times 10^{19}\left[\frac{\mathrm{m}_{\mathrm{e}}^{*}}{\mathrm{~m}_{0}} \frac{\mathrm{T}}{300}\right]^{3 / 2} \mathrm{~cm}^{-3}
$$

The semiconductor band edges are:

$$
\begin{aligned}
& \mathrm{E}_{\mathrm{cn}}-\mathrm{F}_{\mathrm{n}}=-\mathrm{k}_{\mathrm{B}} \operatorname{Tln} \frac{\mathrm{N}_{\mathrm{d}}}{\mathrm{N}_{\mathrm{c}}} \\
& \mathrm{V}_{\mathrm{on}}-\mathrm{V}_{\mathrm{n}}=\frac{\mathrm{qN}_{\mathrm{d}}}{2 \varepsilon_{\mathrm{n}}} \mathrm{x}_{\mathrm{n}}^{2}
\end{aligned}
$$

The contact potential is as follows:

$$
\mathrm{V}_{0}=\frac{\mathrm{E}_{\mathrm{gn}}+\Delta \mathrm{E}_{\mathrm{V}}-\left(\mathrm{F}_{\mathrm{p}}-\mathrm{E}_{\mathrm{vp}}\right)-\left(\mathrm{E}_{\mathrm{cN}}-\mathrm{F}_{\mathrm{N}}\right)}{\mathrm{q}}
$$

Where $E_{g n}$ is energy band-gap of n-type $(\mathrm{eV})$, $\Delta E_{\mathrm{v}}$ is band edge discontinuities $(\mathrm{eV}), F_{\mathrm{p}}$ is Fermi level of p-type (eV), $E_{\mathrm{vp}}$ is valence band edge of $\mathrm{p}$-type material $(\mathrm{eV}), E_{\mathrm{cN}}$ is conduction band level of $\mathrm{N}$-doped material $(\mathrm{eV}), F_{\mathrm{N}}$ is Fermi level of $\mathrm{N}$-doped portion (eV) and $q$ is electric charge (C).

The depletion region width for semiconductor is:

$$
\mathrm{x}_{\mathrm{n}}=\left[\frac{2 \varepsilon_{\mathrm{n}} \mathrm{V}_{0}}{\mathrm{qN}_{\mathrm{d}} \mathrm{N}_{\mathrm{A}}\left(\mathrm{N}_{\mathrm{A}}+\frac{\varepsilon_{\mathrm{p}}}{\varepsilon_{\mathrm{N}}} \mathrm{N}_{\mathrm{d}}\right)}\right]^{1 / 2} \mathrm{~N}_{\mathrm{A}}
$$

Where $N_{A}$ is acceptor concentration $\left(\mathrm{cm}^{-3}\right)$, $N_{\mathrm{d}}$ is donor concentration $\left(\mathrm{cm}^{-3}\right), \varepsilon_{\mathrm{p}}$ is dielectric constant for p-type and $\varepsilon_{N}$ is 
dielectric constant of $\mathrm{N}$-doped material with wider band-gap than $\mathrm{n}$-doped material.

\section{Simulation Results}

The section of simulation results includes three portions: current-voltage characteristic of the device, temperature dependence of energy using Varshni formula and band diagram for donor concentration of $2 \times 10^{17}$ $\mathrm{cm}^{-3}$. Fig. 4 illustrates the current-voltage characteristics of the device. It can be noted that the current condition consists of three portions. They are active region, saturated region and cut-off region. The gate voltages are $4 \mathrm{~V}, 6 \mathrm{~V}$ and $8 \mathrm{~V}$, as observed in Fig. 4.

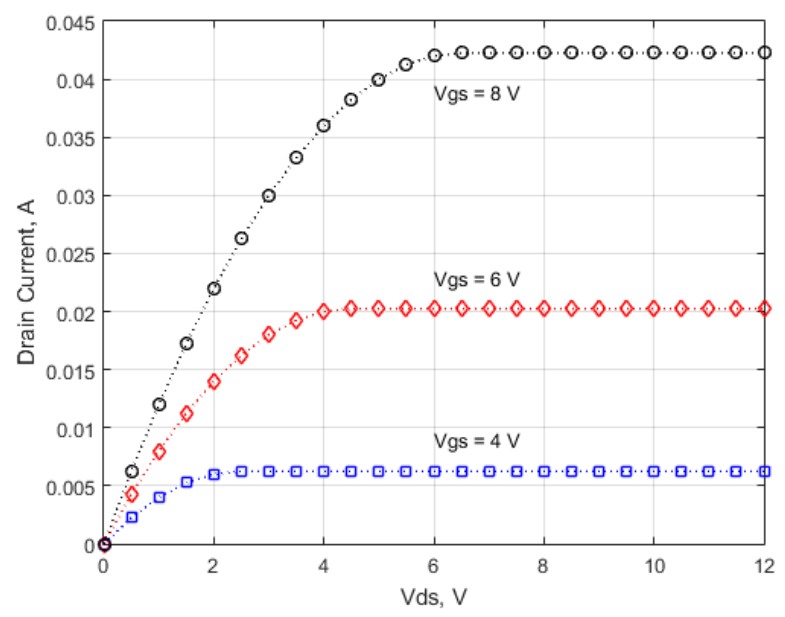

Fig. 4 I-V characteristics of a MOSFET

Fig. 5 shows the temperature variation of band-gap energy for gallium arsenide, silicon and germanium. Among the three types of materials, gallium arsenide has the highest energy level depending on temperature.

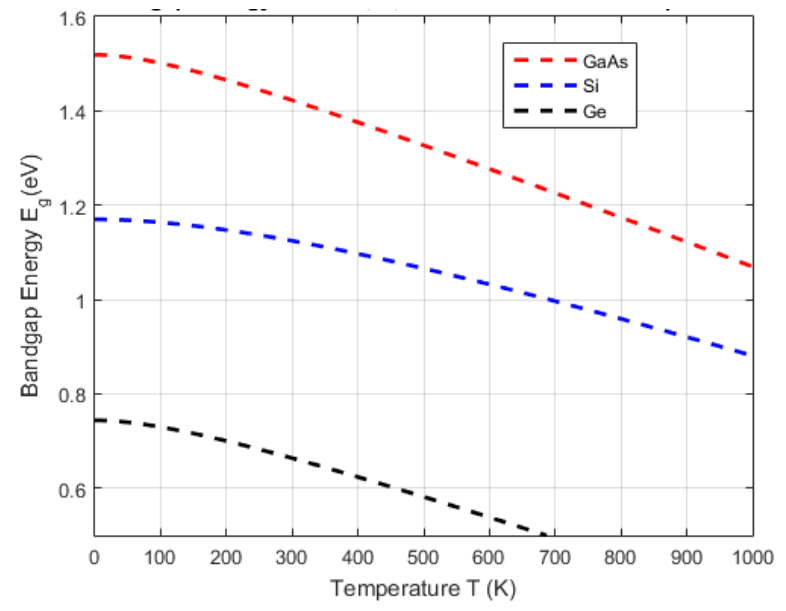

Fig. 5 Band-gap energy GaAs, Si and Ge expressed in terms of temperature

Fig. 6 shows an energy band structure to design the MOSFET. The resultant figure is simulated by using mathematical equations and MATLAB programming language. As can be observed from Fig. 6, the green and the blue lines are for conduction and valence bands of energy diagram, respectively. To complete the transistor modeling, the band structure is considered as metalsemiconductor-metal junctions of the device.

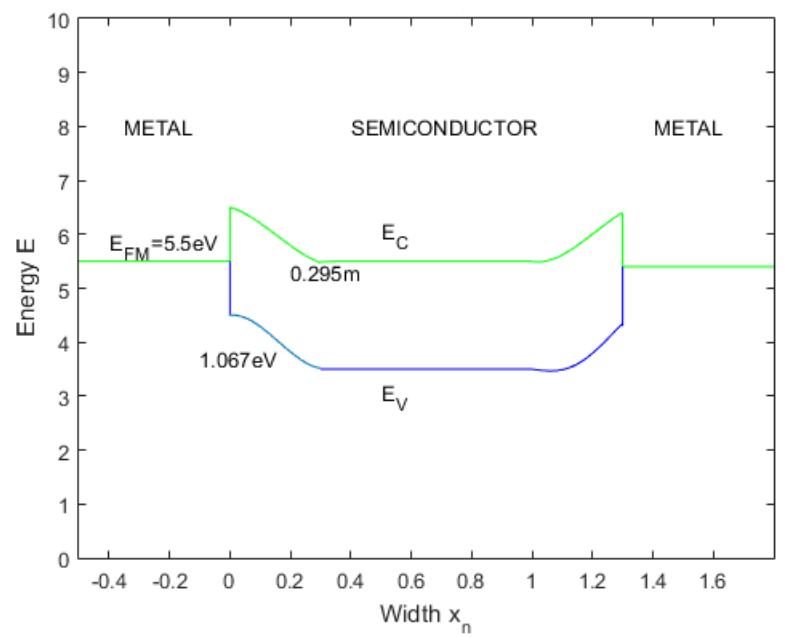

Fig. 6 Band diagram for specific donor concentration, $N_{\mathrm{d}}=2 \times 10^{17} \mathrm{~cm}^{-3}$

\section{Conclusion}

In this paper, the band diagram results are seen to be investigated carefully. Also, the current condition flowing through the device was analyzed by using software simulation method. It was found that the resultant characteristics produce the properties for MOSFET development. Further discussion has been found that other parameters for MOSFET modeling can be tested again.

\section{Conflict of Interests}

The authors declare that there is no conflict of interests regarding the publication of this paper.

\section{Acknowledgement}

The authors wish to thank semiconductor research group of our Technological University.

\section{References}

[1] R. C. Purandare, Investigations on: $A$ homojunction of GaAs using synchrotron radiation, $B$ surface passivation of $\mathrm{GaAs}, \mathrm{PhD}$ thesis, Savitribai Phule Pune University, India, 2004.

[2] R. Clerc, A. Spinelli, G. Ghibaudo, and G. Pananakakis, "Theory of direct tunneling current in metal-oxide-semiconductor structures", J Appl Physics, vol. 91, no. 3, pp. 1400-1409, 2002.

[3] T. E. Schlesinger, "Gallium arsenide" in Encyclopedia of Materials: Science and Technology, 2nd ed., pp. 3431-3435 2001; doi: $10.1016 /$ b0-08-043152-6/00612-4 
[4] E. F. Schubert, Doping in III-V semiconductors, Cambridge University Press: Cambridge, UK, 2004.

[5] W-H. Lee and P. Y. Su, "Single-electron effects in non-overlapped multiple-gate silicon-oninsulator metal-oxide-semiconductor field-effect transistors", Nanotechnol., vol. 20, no. 6, 2009.

[6] A. Challam, C. R. A. J. Chelliah, D. Nirmal, and R. Swaminathan, "Design and fabrication of GaAs based MOSFET by physical vapor deposition method", Materials Focus, vol. 7, pp. 1-6, 2018.

[7] V. O. A. Akpaida, O. Omorogiuwa, and M. S. Okundamiya, Principles of Electronic Devices and Circuits, Stemic Publications: Benin City, 2005.

[8] M. Lundstrom and Z. Ren, "Essential physics of carrier transport in nanoscale MOSFETs", IEEE Trans Electron Devices, vol. 49, no. 1, pp. 133 141, 2002.

[9] R. F. Pierret, Semiconductor Device Fundamentals, Addison Wesley: Boston, MA, 1996.

[10] S. S. Li, Semiconductor Physical Electronics, Springer-Verlag: New York, 2006.
[11] Y. J. Yoon, S. Cho, J. H. Seo, E-S. Cho, S-W. Kang, J-H. Bae, et al., "Design of AlGaAs/InGaAs heterojunction tunneling field-effect transistor for low-standby-power and high-performance application", Int. Conference on Solid State Devices and Materials, Fukuoka, 2013, pp. 178179.

[12] X. Gu, C. W. Myles, A. Kuthi, Q. Shui, and M. A. Gundersen, Gallium arsenide and silicon FETtype switches for repetitive pulsed power applications, Proceedings of the 2002 Int. Power Modulator Conference and High Voltage Workshop, June 30-July 3, 2002, Hollywood, CA, pp. 437-440.

[13] G. Sun, Y. Sun, and T. Nishida, "Hole mobility in silicon inversion layers: stress and surface orientation", J Appl Physics, vol. 102, no. 084501, 2007; doi: 10.1063/1.2795649

[14] B. Van Zeghbroeck, "Principles of Semiconductor Devices", University of Colorado, 2011, https://ecee.colorado.edu/ bart/book/book/titl e.htm (Accessed July 18, 2020) 